\title{
Perkiraan Tinggi Badan Berdasarkan Tulang Panjang Usia 17-22 Tahun
}

\author{
I Gusti Ngurah Putu Sana ${ }^{1}$, Dewa Ayu Agung Alit Suka Astini ${ }^{2}$, I Ketut Tangking \\ Widarsa $^{3}$, I Nyoman Sueta ${ }^{4}$ I Wayan Suwitra ${ }^{5}$, Komang Trisna Sumadewi ${ }^{6}$ \\ 1,2,3,4,5,6 Departemen Anatomi Fakultas Kedokteran dan Ilmu Kesehatan, Universitas Warmadewa, Denpasar \\ ${ }^{2}$ Emailsukesukaastini@yahoo.com
}

\begin{abstract}
Abstrak
Perkiraan tinggi badan sangat penting pada antropologi forensik dalam identifikasi jenasah akan tetapi belum ada model yang baku untuk tujuan tersebut. Penelitian ini bertujuan mengembangkan model perkiraan tinggi badan dengan menggunakan tulang panjang sebagai prediktor. Metode penelitian dengan desain observasional melalui studi cross sectional dilakukan terhadap 96 sampel mahasiswa dipilih secara stratified random dari total 199 mahasiswa yang memenuhi kriteria inklusi, usia 17-22 tahun. Tinggi badan diukur menggunakan ZT-120 Health Scale dan panjang tulang humerus, radius, ulna, femur, tibia dan fibula diukur dengan menggunakan spreading caliper. Model estimasi tinggi badan menggunakan model regresi linier berganda dengan panjang tulang panjang sebagai prediktor. Untuk estimasi tinggi badan laki-laki terdapat tiga tulang sebagai prediktor yaitu tulang tibia kiri, humerus kanan, dan radius kanan dengan koefisien regresi 0,94 $( \pm 0,3), 0,82( \pm 0,3)$, dan $0,79( \pm 0.4)$ secara berurutan. Prediktor untuk tinggi perempuan adalah tulang fibula kiri, ulna kiri, dan humerus kiri dengan koefisien regresi $1,13( \pm 0,3), 1,20( \pm 0,4)$, dan $0,85( \pm 0,4)$ secara berurutan. Dari penelitian ini dapat disimpulkan bahwa tulang tibia kiri, humerus kanan, dan radius kanan dapat dipakai memperkirakan tinggi badan laki-laki dan tulang fibula kiri, ulna kiri, dan humerus kiri untuk tinggi badan perempuan.
\end{abstract}

Kata kunci: tinggi badan, tulang panjang, tibia, fibula.

\section{Abstract \\ [Estimated Stature Based on Long Bone Age 17-22 Years]}

The estimation of stature is very important in forensic anthropology for identification of bodies, but there is no standard model for the purpose. This study aimed to develop a model estimated height, using a predictor of long bones. A total of 96 samples of randomly selected students from a total of 199 students, aged 17-22 years. Height was measured using ZT-120 Health Scale and the length of the humerus, radius, ulna, femur, tibia and fibula was measured by using a spreading caliper. Height estimation model using multiple linear regression model with long bone length as a predictor. to estimate the height of men there are three bones as predictors, the left tibia, right humerus and a right radius, with a regression coefficient of 0.94 ( \pm 0.3$), 0.82$ ( \pm 0.3$)$, and 0.79 ( \pm 0.4$)$ sequentially. Predictors for the high women are left fibula, left ulna and left humerus, with regression koefsien $1.13( \pm 0.3), 1.20( \pm 0.4)$, and $0.85( \pm 0.4)$ sequentially. From this study it can be concluded that the left tibia, right humerus and right radius can be used estimate the height of men, and left fibula, left ulna and left humerus can be used estimate the height of women.

Keywords: stature, long bone, tibia, fibula.

\section{PENDAHULUAN}

Ahli antropologi forensik sering menggunakan tulang untuk identifikasi tinggi badan kasus forensik misalnya pada kasus jasad yang telah dikubur yang hanya tersisa tulang-tulangnya saja, kasus mutilasi, dan fragmen tubuh yang teramputasi akibat adanya bencana alam. ${ }^{[1,2]}$ Panjang tulang panjang (humerus, ulna, radius, femur, tibia, dan fibula) sering digunakan untuk memperkirakan tinggi badan seseorang, karena terdapat hubungan antara panjang biometrik segmen tubuh dan panjang total tubuh. ${ }^{[3]}$ 
Dari beberapa penelitian diketahui bahwa terdapat beberapa tulang panjang yang dapat dipakai memperkirakan tinggi badan. Tulang humerus dan radius terbukti dapat dipakai menentukan tinggi badan seseorang usia 20-30 tahun. ${ }^{[1,4,5]}$ Selain itu, panjang lengan bawah dan panjang kaki dilaporkan berhubungan dengan tinggi badan. $^{[2]}$ Pada penelitian lain ditemukan bahwa panjang tulang tibia pada laki-laki dan femur pada perempuan juga dapat menentukan tinggi badan. ${ }^{[6]}$ Metode yang digunakan untuk memperkirakan tinggi badan seseorang, diantaranya metode anatomis (faktor multiplikasi) dan metode matematik (persamaan regresi). ${ }^{[7]}$

Pada penelitian ini diteliti penggunaan panjang tulang panjang untuk memperkirakan tinggi badan seseorang usia 19 sampai 30 tahun dengan tujuan untuk mengembangkan model regresi estimasi tinggi badan dengan panjang tulang panjang sebagai prediktor. Dari penelitian ini didapatkan bahwa beberapa tulang panjang dapat dipakai memprediksi tinggi seseorang dan tulang yang dipakai memprediksi tinggi laki-laki berbeda dengan tulang yang dipakai memprediksi tinggi perempuan.

\section{METODE \\ Rancangan dan subjek}

Penelitian cross-sectional telah dilakukan terhadap 96 sampel mahasiswa usia 17-22 tahun yang terdiri dari 48 sampel laki-laki dan 48 sampel perempuan. Sampel dipilih secara stratified random dari 199 mahasiswa Fakultas Kedokteran Universitas Warmadewa laki-laki dan perempuan.

\section{Tinggi Badan}

Tinggi badan diukur dalam sentimeter, yang diukur dari puncak kepala (vertex) sampai tumit dengan postur tubuh berdiri tegak (posisi anatomis) dengan ZT120 Health Scale. ${ }^{[7]}$

\section{Panjang Tulang}

Panjang tulang diukur menggunakan spreading caliper. Panjang tulang lengan diukur dengan cara sendi siku dalam fleksi $90^{\circ}$. Panjang humerus diukur dari epicondylus lateralis dan acromion. Panjang radius diukur dari caput radii sampai proccessus styloideus. Panjang ulna diukur dari apeks olecranon ke proccessus styloideus. Panjang femur kiri diukur dengan posisi berdiri dengan kaki kiri sedikit di depan dari kaki kanan dan posisi kaki kiri tidak sepenuhnya diinversikan untuk merelaksasi jaringan lunak dan diukur dari trochanter major ke condylus femoralis. Panjang femur kanan diukur dengan cara sebaliknya. Panjang tibia kiri diukur dengan posisi duduk dengan lutut kiri semifleksi dan kaki kiri tidak sepenuhnya diinversikan untuk merelaksasikan jaringan lunak dan memperlihatkan penonjolan tulang dan diukur dari condylus medialis sampai ujung malleolus medialis. Panjang tibia kanan dilakukan diukur dengan cara sebaliknya. Panjang fibula kiri dilakukan pada posisi duduk dengan lutut kiri semifleksi dan kaki kiri tidak sepenuhnya diinversikan untuk merelaksasikan jaringan lunak dan memperlihatkan penonjolan tulang dan diukur dari titik paling atas caput fibula sampai ke ujung malleolus lateralis. ${ }^{[5,7,8]}$

\section{Analisis}

Perkiraan tinggi badan dilakukan dengan menggunakan model matematik yaitu metode regresi linier berganda. Tinggi badan (Y) sebagai variabel tergatung dan panjang tulang humerus kanan (x1), humerus kiri (x2) radius kanan $(\mathrm{x} 3)$, radius kiri (x4), ulna kanan (x5), ulna kiri (x6), femur kanan (x7), femur kiri (x8), tibia kanan (x9) tibia kiri (x10), fibula kanan (x11), dan fibula kiri(x12) sebagai prediktor. Seleksi prediktor dilakukan dengan metode stepwise. Semua analisis menggunakan tingkat kemaknaan a 5\%.

\section{HASIL}

Sebanyak 96 subyek berpartisipasi pada penelitian ini yang terdiri dari 48 lakilaki dan 48 perempuan. Semua data subyek lengkap dan dapat dianalisis. Umur sampel laki-laki dan perempuan tidak berbeda. Rentang umur sampel laki-laki antara 18-22 tahun dengan rerata $19,8( \pm 0,15)$ tahun dan rentang umur sampel perempuan antara 17- 
22 tahun dengan rerata $19,8( \pm 0,16)$ tahun. Perbedaan panjang tulang panjang laki-laki dan perempuan usia antara 17 sampai 22 tahun disajikan pada Tabel 1. Hasil analisis menunjukan bahwa tulang panjang laki-laki lebih panjang dari perempuan, kecuali tulang femur.

Tabel 1. Karakteristik panjang tulang panjang

\begin{tabular}{lrrr}
\hline \multicolumn{1}{c}{$\begin{array}{c}\text { Jenis } \\
\text { Tulang }\end{array}$} & Laki-laki*) & Perempuan*) & \multicolumn{1}{c}{ P } \\
\hline $\begin{array}{l}\text { Humerus } \\
\text { kanan }\end{array}$ & $32.9( \pm 2.2)$ & $30.2( \pm 1.9)$ & $<0,001$ \\
$\begin{array}{l}\text { Humerus } \\
\text { kiri }\end{array}$ & $32.8( \pm 2.0)$ & $30.0( \pm 1.5)$ & $<0,001$ \\
$\begin{array}{l}\text { Radius } \\
\text { kanan }\end{array}$ & $23.1( \pm 1.8)$ & $20.9( \pm 1.1)$ & $<0,001$ \\
Radius kiri & $23.3( \pm 1,9)$ & $21.3( \pm 1,2)$ & $<0,001$ \\
Ulna kanan & $26.8( \pm 1,6)$ & $24.4( \pm 1,3)$ & $<0,001$ \\
Ulna kiri & $26.8( \pm 1,5)$ & $24.6( \pm 1,4)$ & $<0,001$ \\
$\begin{array}{l}\text { Femur } \\
\text { kanan }\end{array}$ & $33.5( \pm 3,9)$ & $35.5( \pm 3,4)$ & 0,007 \\
Femur kiri & $33.6( \pm 3,6)$ & $35.5( \pm 3,5)$ & 0,012 \\
Tibia kanan & $38.1( \pm 2,4)$ & $35.7( \pm 3,5)$ & $<0,001$ \\
Tibia kiri & $38.1( \pm 2,5)$ & $35.2( \pm 2,3)$ & $<0,001$ \\
Fibula & $39.3( \pm 2,6)$ & $36.5( \pm 1,8)$ & $<0,001$ \\
kanan & $39.2( \pm 2,6)$ & $36.5( \pm 1,9)$ & $<0,001$ \\
\hline Fibula kiri & & &
\end{tabular}

*) Panjang tulang yang disajikan adalah rerata $( \pm$ sd $)$ dalam $\mathrm{cm}$.

Jenis tulang panjang kiri dan kanan yang dapat dipakai memperkirakan tinggi badan laki-laki dan perempuan usia 17-22 tahun berbeda antara laki-laki dan perempuan. Tulang panjang yang dapat dipakai memperkirakan tinggi badan lakilaki adalah tulang tibia kiri, humerus kanan, dan radius kanan dengan nilai $\mathrm{R}^{2}$ dari ketiga prediktor tersebut sebesar 0,82 . Sedangkan pada perempuan adalah tulang fibula kiri, ulna kiri, dan humerus kiri dengan $\mathrm{R}^{2}$ dari ketiga prediktor tersebut sebesar 0,68. Koefisien regresi dan $\mathrm{R}^{2}$ dari masingmasing tulang disajikan pada Tabel 2 .
Tabel 2. Koefisien regresi dan determinasi

\begin{tabular}{lrc}
\hline \multicolumn{1}{c}{ Jenis tulang } & \multicolumn{1}{c}{$\left.\mathbf{b}^{*}\right)$} & $\mathbf{R}^{2}$ \\
\hline Laki-laki: & $89,14( \pm 5,9)$ & \\
Konstan & $0,94( \pm 0,3)$ & 0,72 \\
Tibia kiri & $0,82( \pm 0,3)$ & 0,08 \\
Humerus kanan & $0,79( \pm 0.4)$ & 0,02 \\
Radius kanan & & \\
Perempuan: & $63,33(9,9)$ & \\
Konstan & $1,13( \pm 0,3)$ & 0,54 \\
Fibula kiri & $1,20( \pm 0,4)$ & 0,11 \\
Ulna kiri & $0,85( \pm 0,4)$ & 0,03 \\
$\begin{array}{l}\text { Humerus kiri } \\
\text { *) koefisien regresi b yang disajikan adalah yang } \\
\text { unstandarzied }( \pm \text { SE }) .\end{array}$
\end{tabular}

\section{PEMBAHASAN}

Perkiraan tinggi badan laki-laki dari enam jenis panjang tulang panjang kiri dan kanan, ternyata dari penelitian ini terbukti hanya tiga jenis tulang yang mempunyai kemampuan prediksi yang bermakna, yaitu tulang tibia kiri, humerus kanan, dan radius kanan. Ketiga tulang panjang tersebut dapat memprediksi sekitar $81 \%$ dari variasi tinggi badan laki-laki usia 17-22 ahun. Dari ketiga tulang tersebut, tulang tibia kiri memiliki kemampuan prediksi yang paling baik dari ketiga tulang $\left(\mathrm{R}^{2}=72,4 \%\right)$.

Penelitian sebelumnya pada panjang tibia laki-laki untuk perkiraan tinggi badan menunjukkan korelasi yang kuat $(\mathrm{r}=0,765)$. ${ }^{[6]}$ Penelitian lainnya pada usia 20 sampai 30 tahun, menunjukkan bahwa panjang radius kanan dapat menentukan tinggi badan dengan korelasi yang kuat $(\mathrm{r}=0,846) .{ }^{[4]}$ Namun pada penelitian tulang humerus, menunjukkan humerus kiri memiliki korelasi yang kuat $(\mathrm{r}=0,852)$ untuk menentukan tinggi badan dibandingkan humerus kanan $(\mathrm{r}=849) .{ }^{[5]}$

Model regresi linier perkiraan tinggi badan dengan tulang tibia kiri, humerus kanan, dan radius kanan yang didasarkan pada hasil analis regresi linier berganda adalah: 
$\mathrm{y}=89,14+0,94 \mathrm{x}_{1}+0,82 \mathrm{x}_{2}+0,79 \mathrm{x}_{3}$

Keterangan:

$\mathrm{x}_{1}=$ panjang tibia kiri

$\mathrm{x}_{2}=$ panjang humerus kanan

$\mathrm{x}_{3}=$ panjang radius kanan

Perkiraan tinggi badan laki-laki umur 18-22 tahun dengan menggunakan model tersebut memiliki rerata |residu| terhadap tinggi badan hasil pengukuran sebesar 1,95 $( \pm 0,20) \mathrm{cm}$, maka hasil estimasi tinggi badan yang dihitung dengan model di atas perlu dikoreksi $\pm(1,95+1,96 \times 0,2) \mathrm{cm}$ atau $\pm 2,3 \mathrm{~cm}$. Bila hasil ini dibandingkan dengan hasil dari penelitian lain, maka model ini cukup baik dipakai memperkirakan tinggi badan laki-laki usia antara 18-22 tahun.

Estimasi tinggi badan perempuan dari enam jenis panjang tulang panjang, dari penelitian ini ditemukan tiga jenis tulang yang dapat dijadikan prediktor tinggi badan perempuan umur 18-22 tahun. Ketiga tulang tersebut adalah tulang fibula kiri, ulna kiri, dan humerus kiri. Ketiga tulang panjang tersebut dapat memprediksi sekitar $68 \%$ dari variasi tinggi badan perempuan usia 18 -22 tahun. Dari ketiga tulang tersebut, tulang fibula kiri memiliki kemampuan prediksi yang paling baik dibandingkan ketiga tulang tersebut $\left(\mathrm{R}^{2}=54 \%\right)$.

Penelitian sebelumnya pada tulang humerus menunjukkan humerus kiri memiliki korelasi yang kuat $(r=0,801)$ untuk menentukan tinggi badan dibandingkan humerus kanan $(r=793){ }^{[5]}$ Namun pada penelitian tulang radius, menunjukkan panjang radius kanan menunjukkan korelasi yang kuat $(\mathrm{r}=0,675)$ untuk perkiraan tinggi badan pada perempuan. ${ }^{[4]}$ Penelitian pada tungkai, menunjukkan panjang femur menunjukkan korelasi yang kuat $(\mathrm{r}=0,742)$ untuk perkiraan tinggi badan pada perempuan. ${ }^{[6]}$

Model regresi linier perkiraan tinggi badan dengan tulang fibula kiri, ulna kiri, dan humerus kiri yang didasarkan pada hasil analis regresi linier berganda adalah:

$\mathrm{y}=63,33+1,13 \mathrm{x}_{1}+1,20 \mathrm{x}_{2}+0,85 \mathrm{x}_{3}$

Keterangan:

$\mathrm{x}_{1}=$ panjang fibula kiri $\mathrm{x}_{2}=$ panjang ulna kiri

$\mathrm{x}_{3}=$ panjang humerus kiri

Perkiraan tinggi badan perempuan umur 17-22 tahun dengan menggunakan model tersebut memiliki rerata |residu| terhadap tinggi badan hasil pengukuran sebesar 2,3 $( \pm 0,27) \mathrm{cm}$, maka hasil estimasi dengan model tersebut perlu dikoreksi sebesar $\pm(2,3+1,96 \times 0,27) \mathrm{cm}$ atau $\pm 2,8$ $\mathrm{cm}$. Bila hasil ini dibandingkan dengan hasil dari penelitian lain, maka model ini cukup baik dipakai memperkirakan tinggi badan perempuan usia antara 17-22 tahun.

Penelitian sebelumnya pada panjang lutut-pergelangan kaki dan lengan bawah untuk perkiraan tinggi badan dengan metode regresi linier diperoleh model berupa $\mathrm{Y}=86,772654+2,997967 * \mathrm{X} \quad(\mathrm{Y}$ : tinggi badan, $X$ : panjang lengan bawah) dan $\mathrm{Y}=156,543454+0,296018^{*} \mathrm{X} \quad(\mathrm{Y}$ : tinggi badan, $\mathrm{X}$ : panjang lutut-pergelangan kaki) secara berurutan.

Para ahli antropologi telah melakukan investigasi terhadap beberapa tulang yang memiliki potensi untuk perkiraan tinggi badan, seperti tulang panjang, scapula, clavicula, tulang coxae dan metacarpal. ${ }^{[9]}$ Perkiraan tinggi badan sangat dipengaruhi oleh variabilitas populasi, seperti faktor nutrisi, iklim, migrasi dan genetik. Oleh karena itu satu persamaan perkiraan tinggi badan tidak dapat diaplikasikan pada berbagai populasi. $^{[3]}$

\section{SIMPULAN}

Beberapa tulang panjang dapat
dipakai sebagai prediktor untuk memperkirakan tinggi badan laki-laki maupun perempuan. Tinggi badan laki-laki usia 17-22 tahun dapat diperkirakan dari panjang tulang tibia kiri $\left(\mathrm{x}_{1}\right)$, humerus kanan $\left(\mathrm{x}_{2}\right)$, dan radius kanan $\left(\mathrm{x}_{3}\right)$ dengan model:

$\mathrm{y}=89,14+0,94 \mathrm{x}_{1}+0,82 \mathrm{x}_{2}+0,79 \mathrm{x}_{3}$ dengan koreksi $\pm 2,3 \mathrm{~cm}$ dan perempuan usia 17-22 tahun dapat diperkirakan dari panjang tulang fibula kiri $\left(\mathrm{x}_{1}\right)$, ulna kiri $\left(\mathrm{x}_{2}\right)$, dan humerus kiri $\left(\mathrm{x}_{3}\right)$ dengan model:

$\mathrm{y}=63,33+1,13 \mathrm{x}_{1}+1,20 \mathrm{x}_{2}+0,85 \mathrm{x}_{3}$ dengan koreksi $\pm 2,8 \mathrm{~cm}$. 


\section{UCAPAN TERIMA KASIH}

Kami mengucapkan terima kasih yang tulus kepada semua pihak yang telah berkontribusi terhadap pelaksanaan penelitian ini. Secara khusus kami menyampaikan ucapan terima kasih dan penghargaan kepada Dekan FKIK Unwar yang telah membiayai penelitian ini serta seluruh mahasiswa yang ikut berpartisipasi dalam pelaksanaan penelitian ini sehingga penelitian ini dapat berjalan dengan baik.

\section{DAFTAR PUSTAKA}

1. Kantha LBM, Kulkarni R. Estimation of total length of humerus from its fragments in South Indian population. IJAR 2014;2(1):213-20.Chikhalkar BG, Mangaonkar AA, Nanandkar SD, Peddawad RG. Estimation of stature from measurements of long bones, hand and foot dimensions. $J$ Indian Acad Forensic Med 2009; 32(4):329-3.

2. Shields KJ. The importance of individual and population variation to human stature estimation. Bachelors of Arts, University of Montana, Missoula, Montana. 2005.
3. Borkar MP, Hattangdi SS. Estimation of height from the length of radius in Western Region of Maharashtra. International Journal of Recent Trends in Science And Technology 2014;9(3): 427-2.

4. Borkar MP. Estimation of height from the length of humerus in western region of Maharashtra. Int $J$ Res Med Sci 2014;2(2):498-2.

5. Bhavna, Nath S. Use of lower limb measurements in reconstructing stature among Shia Muslims. ISPUB 2008;2 (2).

6. Gadekar S, Vaishnani H, Vikani S, Gujaria IJ, Bondre KV, Shah1 GV. A study to correlate the stature with the length of ulna in living humans in various age groups. IJBAR 2012;03 (12):904-3.

7. Pan N. Length of long bones and their proportion to body height in Hindus. $J$ Anat 1924;58:374-78.

8. Brandt ET. Stature wars: which stature estimation methods are most applicable to modern populations? Thesis Texas State University-San Marcos. 2009. 